\title{
A instituição da "Física de Partículas Elementares" como disciplina científica e sua relação com a formação de professores ${ }^{+*}$
}

Antonio Augusto Passos Videira ${ }^{1}$

Universidade do Estado do Rio de Janeiro

Mariana Faria Brito Francisquini ${ }^{2}$

Instituto Federal de Educação, Ciência e Tecnologia do Rio de Janeiro

Niterói - RJ

\section{Resumo}

O debate acerca da consolidação de uma nova área como disciplina científica não é um assunto devidamente explorado na literatura, à parte sua importância para a formação de professores. Ao contrário do que se poderia imaginar, as disciplinas científicas não são uma maneira espontânea de como os fenômenos se apresentam na natureza. Elas são resultado da atividade humana; tendo, cada disciplina, sua própria história. Com o objetivo de reforçar essa tese, apresentaremos o exemplo da constituição da Física de Partículas Elementares como disciplina científica. Por meio desse episódio, pretendemos também mostrar como questões epistemológicas podem ser discutidas durante a formação dos professores a fim de obterem uma visão mais clara sobre os processos pelos quais a ciência se desenvolve.

Palavras-chave: Disciplinas Científicas; Física de Partículas Elementares; Comunidade Científica; Estudos Científicos.

\footnotetext{
+ The institution of "Elementary Particle Physics" as a scientific discipline and its relation to teacher training

* Recebido: março de 2017. Aceito: setembro de 2017.

1 E-mail: guto@cbpf.br. O autor agradece os apoios financeiros do CNPq através da uma bolsa de produtividade e da UERJ através do Programa Prociência. ${ }^{2}$ E-mail: mariana.francisquini@ifrj.edu.br
} 


\begin{abstract}
The debate regarding the consolidation of a new area as a scientific discipline is not a well explored issue in the literature, albeit its relevance to teacher training. On the contrary to what one might think, scientific disciplines are not a spontaneous manner of how phenomena appear in nature. They are product of human creation, and each one has its own history. In order to reinforce this thesis, we shall introduce the case of the constitution of Elementary Particle Physics as a scientific discipline. By this episode, we also intend to show how epistemological issues can be raised during the process of teacher training in order for them to gain a clearer picture of the processes through which science develops itself.
\end{abstract}

Keywords: Scientific Disciplines; Elementary Particle Physics; Scientific Community; Science Studies.

\title{
I. Introdução
}

Uma das grandes preocupações de professores no exercício de sua profissão diz respeito à constituição do currículo. Ele é muitas vezes estruturado a partir de uma gama de diferentes assuntos que são, no caso da física, apresentados de uma maneira conteudística e ahistórica em praticamente todos os níveis de instrução. Essa abordagem desvia a atenção do professor a outras questões pertinentes ao ensino e aprendizagem de sua matéria, como: o que deve compreender um currículo de física? Quais disciplinas são essenciais para garantir o sucesso desse currículo? O debate sobre a adequação dos conteúdos curriculares há muito tem sido alvo de publicações em periódicos, teses e dissertações. Não menos debatida é a questão da incorporação dos conteúdos da Física Moderna e Contemporânea em sala de aula. Se, por um lado, não estamos colocando em pauta a necessidade de inserção desse conteúdo ao currículo; por outro, já se pode encontrar na literatura um consenso acerca da importância do ensino da Física de Partículas Elementares dentro do conteúdo da Física Moderna a nível básico (PIETROCOLA; SIQUEIRA, 2012, p.263). Além disso, os alunos vêm sendo expostos a este domínio, tanto por parte da mídia quanto por parte de outros veículos de comunicação, sem que ele seja apresentado nas salas de aula. Por este motivo, o tratamento desses temas deve ser trazido para a alçada do professor ainda que de maneira subsidiária - em oposição àquela de um programa rígido - e o processo de evolução de uma disciplina científica pode ser um ponto de partida interessante para este objetivo.

A historiografia reporta que, até 1948, a Física de Partículas Elementares ainda não existia como disciplina e o termo "Física de Altas Energias" ainda não havia entrado no vocabulário do físico profissional (KRAGH, 2002, p. 312). O professor de física poderia questio- 
nar-se por que, então, em setenta anos se discutiria tanto sobre a inserção deste assunto nos programas oficiais. Uma tentativa de resposta a esta pergunta é mitigada a partir do momento em que se sugere a naturalização da disciplina; ou seja, quando se identifica que ela engloba o estudo dos fatos tal como eles se apresentam na natureza. Sua origem constitui uma oportunidade na formação do professor de refletir sobre questões que transcendem os conteúdos disciplinares, mas concorrem para melhorar seu senso crítico e sua maneira de abordar temas em sala a fim de formar um aluno igualmente crítico. Em que espaço e tempo esta etapa tem de ser contemplada se não na universidade durante a instrução do futuro professor?

Este episódio também suscita questões epistemológicas cujas respostas não são encontradas no interior da ciência. Entre muitas outras, poderíamos nos perguntar: que valores epistêmicos são evocados quando analisamos a formação de uma nova área? Ou, ainda, o que pode ser caracterizado como uma disciplina científica e em que condições uma nova disciplina é criada? Neste sentido, as contribuições da História, da Filosofia e da Sociologia da Ciência (HFSC) se mostram não apenas auxiliares ao exercício da prática docente, mas fundamentais. A esse respeito, antes mesmo da década de 1980 já eram conhecidos trabalhos (SCHWAB, 1964; ENNIS, 1979) que enfatizavam a importância de se conhecer as estruturas das disciplinas científicas, seus valores, explicações e teorias. Esses tópicos devem integrar um interesse permanente a todos os professores no exercício de sua função, uma vez que eles contribuem com o progresso do conhecimento não apenas dos conteúdos da sua área, mas também do conhecimento sobre sua área (MATTHEWS, 1994). Essa perspectiva de se propagar uma certa concepção de ciência é compartilhada não só por teóricos da educação, mas também por cientistas de renome. Um exemplo emblemático é o da palestra proferida em 1982 por Mario Schenberg, expoente da física teórica no Brasil, no Salão Nobre do Observatório Nacional, em que destaca:

Tem que haver determinadas sociedades, associações e instituições que estimulem o interesse pela Ciência, que estimulem uma certa compreensão da Ciência. Compreender a Ciência não é somente conhecer os resultados: é saber como algo foi descoberto ou o que significa realmente ${ }^{2}$. As instituições brasileiras deviam operar dentro desta filosofia de estímulo à pesquisa já em nível de escolas secundárias ou, pelo menos, no começo do curso universitário (SCHENBERG 1991) ${ }^{3}$.

A respeito do meio pelo qual se poderia atingir os objetivos acima delineados, e indo ao encontro das ideias aqui supracitadas, Schenberg é categórico ao enfatizar que:

A História da Ciência é o único veículo através do qual podemos ter conhecimento de certos fatos. Pelos estudos dos grandes cientistas ou pelo contato direto com ele podemos ter uma ideia do que seja realmente fazer Ciência (SCHENBERG 1991).

\footnotetext{
2 Grifo nosso.

${ }^{3}$ Embora a palestra tenha sido realizada em 1982, o texto só foi publicado em 1991.
} 
Ainda que não use a expressão explicitamente, Schenberg, em ambos os trechos acima, parece recorrer à noção de prática científica para sinalizar qual deve ser a atitude de todo aquele que pretende entender e ensinar ciência. Tomemos a questão da constituição da matéria como tema para a aplicação da atitude preconizada pelo físico pernambucano.

Os componentes últimos da matéria há muito são objeto de interesse por parte dos seres humanos. Dos gregos até os dias de hoje, podem-se citar muitas tentativas de descrições e de proposições modelos para melhor entendê-los ou para explicar seu comportamento. No entanto, somente no século XX observamos este domínio sendo transformado em uma disciplina científica. O que faz com que uma preocupação tão antiga se torne um novo campo de pesquisa? Considerando-se que o conhecimento gerado em um novo domínio não provém de fatos já consolidados ao longo dos séculos - mas sim de novas observações e interpretações pretendemos fornecer um exemplo de como questões históricas, filosóficas e sociológicas podem contribuir com a narrativa do episódio de formação de uma disciplina científica. Mais concretamente, pretendemos enfatizar estas características na elaboração da Física de Partículas Elementares tal como a definimos hoje, seja "lidando com as mais ínfimas partículas de construção do mundo e de nós mesmos" (OKUN, 1987, p. 2) ou "lidando com o estudo dos constituintes últimos da matéria e da natureza das interações entre eles" (PERKINS, 1986, p. 1). Para isto, apresentaremos a visão de disciplina que vem sendo incentivada, juntamente de suas funções; o papel das comunidades científicas na formação e estabilização das disciplinas e uma breve narrativa da situação em apreço.

\section{As disciplinas científicas}

Durante muito tempo as disciplinas científicas foram concebidas como áreas cumulativas do conhecimento. Hoje em dia, elas são mais bem entendidas como corpos provisórios de conhecimento que se relacionam a outros campos do conhecimento, incorporando técnicas, instrumentos, teorias e modelos, muitas vezes oriundos de setores que lhes são externos. Desde o início de sua institucionalização no século XVIII, elas se mostram partes relevantes da prática científica e o fato de tal conceito possuir uma pré-história muito anterior ao século XVIII, e continuar em voga nos dias de hoje, mostra a importância desta estrutura no empreendimento científico. No entanto, uma visão tradicional, pautada no conhecimento de leis e princípios gerais, pode sugerir que as disciplinas sejam composições rígidas formadas unicamente para organizar a ciência. Este não é o caso. Ao contrário, há uma tendência (STICHWEH, 1992; GUNTAU; LAITKO 1991) em tratá-las como estruturas que garantem o caráter dinâmico à ciência, contrariamente à visão de que seriam produtos de fontes monocausais. Podem ser descritas, desta forma, como o efeito de sistemas que interagem entre si. É por meio dessas redes de interação que o conhecimento e as práticas ganham legitimidade na comunidade científica, no governo e na sociedade, de modo a estabilizar seus objetos de estudo. Aceitar essa tese significa romper com a crença na teleologia de uma ideia central e, tão importante quanto, aceitar o fato de que ninguém cria disciplinas (LENOIR, 2004). 
Alguns dos trabalhos que as tratam como áreas isoladas do conhecimento, como a "Classificação das ciências", por exemplo, sofrem críticas no que diz respeito à sua abrangência. Isso ocorre ao sugerir-se que a classificação do mundo físico e a classificação das ciências devam manter uma relação de analogia entre si. Assim, os três reinos da natureza: vegetal, animal e mineral estariam ligados, respectivamente, aos campos do conhecimento conhecidos como: botânica, zoologia e mineralogia. $\mathrm{O}$ fato de não conseguirmos enquadrar todo e qualquer objeto neste esquema - como os objetos da física - permite afirmar que o entendimento da disciplina como campo de conhecimento possui limites. A naturalização das disciplinas tal como propagada nas academias e internalizada por estudantes das licenciaturas produz aspectos "artificiais" em relação à ciência: como se elas fossem uma consequência de sua universalidade e, em vista disso, refletissem o inevitável progresso científico pelo qual supostamente passamos. Em nosso entendimento, estas estruturas não devem ser entendidas como informações que cumulativamente se somam em conteúdos a serem aprendidos, sem um começo e sem um fim temporais. Ou, ainda, entendidas como se o mundo se apresentasse de uma maneira inerte (ou estática), como que à espera da intervenção humana para descobrir seus objetos e chegar a seus princípios gerais. O que pouco se discute acerca das disciplinas científicas é que elas são uma invenção humana e, como tais, têm uma história, passando por processos de criação, evolução e consolidação. Desta maneira, devem ser entendidas não mais como o "produto de um evento único, de um impulso fundador ou de uma inovação institucional; mas como o resultado imprevisível e cumulativo 4 de inovações e mudanças" (STICHWEH, 1992, p. 4). Por este motivo, devemos considerar o caráter inacabado das disciplinas científicas, concebendo os momentos de formação e de permanente mudança como inerentes à prática científica.

A mudança referida não deve ser entendida como ocorrendo apenas no conteúdo das disciplinas, mas também na sua função. Até o século XVIII, uma das principais funções das disciplinas era simbolizar o grau de verdade atribuído a um domínio (STICHWEH, 1992). Essa função era desempenhada por meio de sua organização hierárquica nas enciclopédias. No século XIX, com a transição desta disposição para uma listagem alfabética, a noção de verdade de um domínio não estava mais relacionada à localização privilegiada deste campo nas primeiras entradas das enciclopédias. Com isso, a ideia de hierarquia foi mitigada de modo que as disciplinas pudessem coexistir representando sistemas equiparados, de igual valor.

Outras funções, no entanto, permanecem fiéis em essência em relação à época em que as disciplinas começaram seu processo de institucionalização. Algumas destas funções dizem respeito: à estruturação de relações do cientista com contextos institucionais; à estabilização da heterogeneidade da ciência e à reformulação dos seus objetos - por meio da correção dos erros científicos - para estabilizá-los e, com isto, legitimar as técnicas e práticas internas à

\footnotetext{
${ }^{4} \mathrm{O}$ termo não deve ser entendido como que sugerindo o acúmulo de informações no interior da disciplina como delineia a tradição; tampouco como um acúmulo linear de fatos na história da ciência. Ele deve ser entendido como sugerindo uma rede de relações causais que, apenas quando tomadas conjuntamente, concorrem para o surgimento da disciplina.
} 
disciplina. Essa lista não é exaustiva. Escolhemos tais características por estarem relacionadas à questão da autonomia da ciência, fundamentada na universalidade, na racionalidade e na objetividade da prática científica. Esta, face à sua autonomia, tinha a pretensão de chegar à verdade e, para isso, necessitava encontrar o suporte institucional que supostamente garantiria este objetivo (LENOIR, 2004). Esta estrutura materializada na forma de livros, bibliotecas, laboratórios e disciplinas, também ditaria os modos pelos quais o conhecimento produzido poderia ser aplicado e distribuído na sociedade. No entanto, mesmo esta institucionalização precisaria encontrar uma justificativa. Aliás, não apenas ela, mas também os motivos a favor do financiamento - em especial, o público - para suas pesquisas e atividades (OLIVEIRA, 2017). A natureza desta justificativa poderia, então, compreender diversos argumentos. Ora poderia o cientista fundamentá-la em razão do bem da sociedade ou, ainda, em razão de algo que transcendesse a própria prática, como o valor de verdade (ZIMAN, 1981).

Nesta perspectiva, podemos ser levados em outra direção, uma não tão óbvia, mas que se faz presente em todas as funções acima de uma maneira mais ou menos explícita: a relação entre a as disciplinas e a metafísica. Ou seja, será que a formação de uma disciplina científica pode manifestar a presença de uma metafísica? Se sim, em que momento? Na sua justificativa institucional? Ou na medida em que os cientistas se valem daquilo que os instrumentos exibem para se chegar à constatação de regularidades ou à formulação de leis e teorias, como pretensão de se chegar à verdade (VIDEIRA, 2013)?

\section{O realismo científico, as disciplinas e sua metafísica}

A questão do realismo científico permeia muitos debates relativos à prática científica (HACKING, 1983; CARTWRIGHT, 1983). Este debate justifica-se por não se poder prová-lo por meio de um método racional. Ao contrário, ele é uma consciência que temos quando, ao utilizar uma teoria, verificamos que suas proposições nos fornecem informações de caráter preditivo sobre o mundo real. Caso não o façam, temos de trabalhar nas nossas hipóteses e adequar nossas teorias aos fenômenos. Em outras palavras, uma disciplina científica engloba objetos, leis, teorias, modelos, proposições consideradas verdadeiras, assim como sua própria maneira de reformular tais proposições e valores de diferentes tipos (simplicidade, objetividade, fecundidade, entre outros) (SILVA, 2017). Não há disciplina despida de um caráter de constante atualização, sendo os erros as principais fontes desta atualização. Sob esta ótica, uma disciplina científica qualquer pressupõe um conhecimento de natureza não-científica, portanto metafísico. Por exemplo, quais critérios um enunciado deveria satisfazer para ser considerado científico? Ou, ainda, que valores evocar para se escolher uma teoria ou modelo em detrimento de outra?

Não se pode responder estas questões sem a menção a uma comunidade científica. As disciplinas científicas devem incorporar um conjunto de pessoas que, através de pesquisas e publicações, impulsionam o desenvolvimento da disciplina, definem critérios de cientificidade de um enunciado e podem se considerar pertencentes àquela comunidade. Esta, por sua 
vez, desenvolve vocabulários específicos, comunicações internas às pessoas pertencentes a ela e fundam sociedades de especialistas (ZIMAN, 1981). Assim sendo, os integrantes destes grupos se relacionam uns com os outros a partir: "da existência de valores comuns, do conhecimento tácito de técnicas de resolução de problemas que só podem ser transferidos via interação de pessoa para pessoa e de divisões tácitas do trabalho ou de relações de competitividade que são possíveis apenas porque cada um sabe dos problemas sendo resolvidos pelos outros" (STICHWEH, 1992, p. 9).

Em 1969, no posfácio de sua principal obra “A Estrutura das Revoluções Científicas", Kuhn já destacava o componente metafísico em uma matriz disciplinar, afirmando estar fundamentado no compartilhamento de crenças comuns entre cientistas. Segundo ele, tais comprometimentos seriam descritos como crenças em modelos particulares. Esses modelos, à parte sua natureza heurística ou ontológica, teriam todos a mesma função: fornecer analogias e metáforas ao grupo de cientistas. Desta maneira, eles ajudariam a determinar o que poderia ser considerado uma explicação ou resolução de charada (KUHN, 1962; MENDONÇA, 2012).

Além disso, a presença de valores comuns contribui para desenvolver no cientista o sentimento de pertencimento à comunidade. Embora os valores sempre estejam presentes na sua prática, eles têm "particular importância quando se deve escolher entre modos incompatíveis de praticar a sua disciplina" (KUHN, 1962, p. 182). Sejam estes relativos à predição ou julgamento de teorias ou valores como simplicidade, consistência e plausibilidade, por exemplo. A formação de uma disciplina científica e o pertencimento do cientista a uma comunidade conferem um grau de identidade à prática do cientista. Com o aumento de investimentos, especializações, equipamentos tecnológicos e, com estes últimos, a detecção de objetos postulados pelos cientistas, esta prática ganha legitimidade perante a sociedade e outras comunidades científicas. Como consequência, embora a função da disciplina hoje não seja mais conferir o grau de verdade a um domínio, como ocorria no século XVIII, ela acaba produzindo uma concepção de real que é desenvolvida e transmitida $\boldsymbol{n a}$ disciplina a cidadãos, cientistas e/ou futuros professores. Isso concorre para a crença na universalidade da ciência, uma vez que tal concepção evita o surgimento de uma pluralidade de visões de mundo.

Apresentaremos, a seguir, uma breve descrição sobre a constituição da Física de Partículas Elementares como disciplina científica no século XX, sendo esta narrativa, como qualquer outra, fruto de escolhas. As nossas basearam-se em não apenas mostrar que a física é um empreendimento feito pelo homem, em seu espaço e tempo em colaboração com outros grupos, mas também mostrar que este episódio gera questões sobre o "fazer ciência" que podem e devem ser exploradas em sala de aula. Apenas para citar uma delas: o fato de que a física é uma ciência em constante mudança e que, apesar de pautar-se em critérios racionais, não obedece a um método rígido, mas "trabalha com evidências disponíveis para construir-se a melhor explicação possível" (STANLEY, 2016, p. 43). Assim, este trabalho também se quer como um convite a futuros professores sobre o debate a respeito dos "métodos da ciência". 
Oportunidade esta gerada pela situação aqui trazida, uma vez que em nenhum outro episódio na história da ciência parece ter havido uma mudança no plano epistêmico dos valores na física no que diz respeito à função da natureza como neste caso. Na ocasião em apreço, seu papel parece ser meramente simbólico no processo de produção do conhecimento científico. Em termos mais específicos: na física contemporânea, a dupla descoberta do méson $\pi$ (dentro e fora do laboratório) exibe que apenas a natureza parece não dispor de capacidade epistêmica suficiente para comprovar as leis e os modelos propostos pelos cientistas. Contudo, deve ser observado que não apenas a função da natureza é reforçada no exemplo que se segue. Outro ponto interessante ao nosso objetivo é destacar o papel que a circulação do conhecimento, isto é, de especialistas e instrumentos, desempenha na criação e consolidação de novas áreas e linhas de pesquisa. Em suma, pretendemos mostrar que a ideia de formação de uma disciplina científica, além de apresentar debates epistemológicos relevantes ao ensino, parece se aplicar ao caso da física de partículas elementares que surge por volta do ano de 1948 como sugere a historiografia (BROWN, 1983; FOSTER; FOWLER, 1988).

\section{O méson $\pi$ e a "disciplinarização" da Física de Partículas Elementares}

A descrição das partículas elementares é um dos problemas mais importantes da física moderna (LOPES, 2004). No entanto, o assunto está longe de ser uma preocupação nova. A busca pela constituição de toda a matéria conhecida no universo teria tido início com os gregos e a ideia inicial de átomo teria sido introduzida na filosofia principalmente por Leucipo e Demócrito (CARUSO; OGURI, 1996). Do átomo de Demócrito ao átomo dos dias de hoje, muitas foram as concepções, imagens e modelos (filosóficos ou científicos) relacionados à matéria e listá-los à exaustão não se insere no escopo desde trabalho. Ao nosso objetivo, interessa-nos que a descoberta do elétron e, posteriormente, do próton, estabeleceu na comunidade científica a convicção de que estas partículas seriam constituintes fundamentais da matéria. Uma das primeiras descrições modernas do átomo foi posteriormente proposta por Rutherford no famoso episódio da história da ciência em que bombardeou partículas alfa contra uma folha fina de ouro. $\mathrm{O}$ fato de que grande parte das partículas atravessava a folha sem sofrer deflexão, e outras poucas eram defletidas, voltou a atenção dos físicos para a explicação das propriedades dos elementos como sendo formados por prótons e elétrons.

O modelo de Rutherford, apesar de elucidativo, não condizia com o eletromagnetismo clássico. Se os elétrons orbitassem ao redor do núcleo, eles deveriam emitir energia continuamente e em algum momento deveriam colidir-se com ele. O resultado desse embate foi resolvido por Niels Bohr (1885-1962) ao postular que os elétrons só pudessem ser encontrados em determinadas órbitas denominadas "estacionárias" e que ao passar de uma órbita para outra, eles deveriam absorver (ou emitir) energia radiante de determinada frequência. A aceitação da teoria de Bohr foi quase que imediata porque oferecia uma justificativa teórica para os resultados empíricos da série de Balmer, do princípio da combinação de Ritz e da constante de Rydberg (LOPES, 2004, p. 61). 
Posteriormente, foi prevista a existência de um corpúsculo com energia positiva e carga oposta à do elétron por meio de cálculos teóricos. A primeira reação seria previsivelmente sugerir que esta entidade pudesse ser o próton, como o fez Dirac. A teoria previa, no entanto, uma partícula de massa igual à do elétron. Em 1933, Carl D. Anderson, P. M. S. Blackett e Occhialini encontraram experimentalmente o corpo postulado, o qual mais tarde ficaria conhecido como pósitron (WEINBERG, 1993, p. 160). A época que compreende a previsão e descoberta do pósitron e de outra partícula subnuclear, o méson $\pi$, nos é central neste trabalho.

Uma das teses mais difundidas entre os membros da comunidade de física de partículas elementares é aquela que afirma que o seu nascimento teria ocorrido entre os anos de 1947 e 1948, quando em duas ocasiões experimentais radicalmente distintas o méson $\pi$ fora descoberto (FOSTER; FOWLER, 1988, p. xi). A confirmação da existência dessa partícula, prevista teoricamente anos antes pelo físico japonês Hideki Yukawa, é geralmente compreendida como inaugurando uma nova era na física (PAIS, 1986, p. 511). No entanto, esta visão internalista acaba reforçando o mito de que uma disciplina nasce a partir de ideias, entidades ou pessoas fundadoras (LENOIR, 2004). Contra essa perspectiva, colocaremos em xeque a afirmação de que a física de partículas elementares tenha surgido com a confirmação da existência do méson $\pi$. O pressuposto para a aceitação dessa tese é o papel desempenhado pelo píon na confirmação do modelo de Yukawa. Contudo, o píon não foi a primeira partícula "descoberta" em raios cósmicos, como já citado. Antes houve o caso do pósitron. Por que, então, o píon e não o pósitron? O relevante, neste caso, é que as condições da confirmação do píon se deram em um acelerador de partículas e não apenas na "natureza". Estas condições poderiam corresponder a uma mudança no plano dos valores epistêmicos da ciência?

Em 1947, a confirmação da observação da partícula prevista por Yukawa se deu em plena Cordilheira dos Andes, no Monte Chacaltaya (Bolívia), a 5200 metros de altitude. No ano seguinte, a sua existência foi confirmada no cíclotron de Berkeley, na costa oeste dos EUA. Em ambas as oportunidades, esteve presente o físico brasileiro Cesar Lattes (19242005), personagem importante devido ao seu conhecimento no uso da técnica de emulsões nucleares. Aquela primeira observação do méson $\pi$, não foi a primeira oportunidade em que os raios cósmicos foram utilizados para provar a existência de uma nova (no sentido de até então desconhecida) partícula elementar (VIEIRA; VIDEIRA, 2014). No início da década de 1930, Anderson, Blackett e Occhialini, este último também participante da primeira descoberta do méson, provaram que o pósitron existia. Relembrar o pósitron nos permite indagar pela coerência da historiografia usual que atribui ao píon a responsabilidade pela criação de uma nova área na física.

Em artigo publicado na revista Nature, em 1947, intitulado Nuclear disintegrations produced by slow charged particles of small mass (OCCHIALINI; POWELL, 1947), o qual parece ser um dos primeiros artigos de uma série que se referirá ao tema da Física de Partículas Elementares, Occhialini e Powell fazem a análise do espalhamento de partículas em que 
utilizavam a técnica denominada método fotográfico ou emulsões nucleares (VIEIRA 2012). Neste trabalho, as conclusões dos autores são desenvolvidas na tentativa de se mostrar o porquê de o método empregado ser confiável. A respeito disso, eles destacam:

$O$ acordo entre os resultados de observadores em dois laboratórios diferentes, trabalhando de maneira completamente independente com materiais diferentes, é uma prova definitiva da confiabilidade do método fotográfico no seu estado presente de desenvolvimento.

No entanto, este relato pode ser visto não como prova definitiva da confiabilidade de um método, mas como prova de uma outra característica da ciência: sua desunificação (STUMP; GALISON, 1996; VIDEIRA, 2005). Uma vez que cientistas, mais especificamente físicos, apresentam-se em comunidades com diferentes práticas, interesses e tradições, determinar um consenso sobre um resultado experimental não constitui uma tarefa trivial. Neste sentido, devemos entender que esta concordância sobre um fenômeno intrigante ou sobre o grau de confiabilidade de um método confere legitimidade aos resultados obtidos pelos grupos. Entender que a estabilização da prática científica ocorre no nível comunitário contraria a concepção que se tem dos homens e mulheres da ciência como sendo pessoas geniais e à parte de todas as outras. O modo pelo qual se realiza tal processo é, entre outros, mediante a manipulação de instrumentos. Como exemplo, podemos citar a relevância do primeiro acelerador circular de partículas (cíclotron), construído em 1931 pelo físico norte-americano Ernest Lawrence (1901-1958). Como herança, aceleradores maiores seriam propostos e construídos. O uso dessas máquinas ganhou destaque com o Projeto Manhattan, o qual coordenou a grande mobilização científico-militar para a construção das bombas atômicas lançadas sobre o Japão em agosto de 1945.

O papel da instrumentação continuaria ganhando popularidade no discurso do cientista. Ao fazer o balanço de um encontro científico ocorrido em julho de 1953, em Bagnères de Bigorre (França), o físico francês Louis Leprince-Ringuet (1901-2000) escreveu que o destino da pesquisa na área de raios cósmicos dependia dos aceleradores de partículas (LEPRINCE-RINGUET, 1953, p. 189). Em seus termos:

Para terminar com algumas palavras, pode-se sem dúvida dizer que o futuro da radiação cósmica no domínio da física nuclear depende das máquinas especialmente com o desenvolvimento mais ou menos rápido do "strong focusing", mas é provável que esta seja uma perspectiva somente parcial.

Dois anos depois, tal previsão seria confirmada em um encontro em Pisa (Itália). Lá, a predominância dessas máquinas foi tamanha que levou Juan G. Roederer a resumir a quantidade de dados, apresentados à reunião pelos norte-americanos, com o adjetivo de "toneladas". Os aceleradores ofereciam não só abundância na produção de mésons, que, até então, só haviam sido produzidos e detectados nos raios cósmicos. Aquelas máquinas - cujos tamanhos e custos cresciam rapidamente - permitiam aos físicos algo tão ou mais valioso que a quanti- 
dade: o controle sobre a produção de tais eventos. Estas características (quantidade e controle) tornariam as análises mais confiáveis e seguras (GALISON, 1997). Apesar disso, o ofício do cosmicista passa a depender de um parâmetro crucial: a aleatoriedade dos eventos em seu detector. Por este motivo, captar um integrante ainda desconhecido do universo subatômico não seria uma tarefa fácil.

Com o final da guerra, houve a retomada do uso dos aceleradores para a pesquisa básica. Em um deles, Lattes e o físico norte-americano Eugene Gardner (1917-1950) obteriam, em 1948, um resultado de grande repercussão, tanto científica quanto política. Neste ano, Lattes chegara ao Laboratório de Radiação, na Universidade da Califórnia, em Berkeley (EUA), chefiado por Lawrence e que abrigava o então mais potente acelerador de partículas do mundo: o sincrocíclotron de 184 polegadas. O sincrocíclotron havia sido construído com o objetivo de produzir mésons - até então encontrados apenas na radiação cósmica. Porém, mais de um ano depois do início do funcionamento do sincrocíclotron, em 1 de novembro de 1946, os mésons ainda não haviam sido detectados nos choques das partículas alfa contra alvos fixos (TAVARES, 2017). As partículas geradas nessas colisões tinham suas trajetórias registradas nas emulsões nucleares. Naquele momento, Lawrence não se encontrava em uma situação fácil de ser solucionada.

A situação sofreria, no entanto, uma reviravolta cerca de dez dias depois da chegada de Lattes a Berkeley. Quando examinadas as emulsões ao microscópio, Lattes conseguiu identificar as trajetórias dos píons. Sua conclusão: o sincrocíclotron estaria produzindo mésons desde que começou a funcionar, estas partículas só não estavam sendo reconhecidas nas emulsões. Desta forma, Lattes não só aumentou o tempo de varredura ao microscópio, mas também acrescentou à pesquisa o conhecimento que havia adquirido em 1946 e no ano seguinte, trabalhando no Laboratório H. H. Wills, na Universidade de Bristol, na Inglaterra. Lattes sabia reconhecer os traços dos mésons nas emulsões, ou seja: sabia o que buscar ao microscópio. Este caso poderia ser caracterizado, no mínimo, como curioso. O reconhecimento destas partículas nas emulsões nucleares só foi possível devido ao longo processo de especialização pelo qual a ciência passou. Contudo, este nível de especialização exige do cientista um alto grau de familiaridade com o instrumento com que opera, a fim de que se extraiam dados relevantes à prática. Como poderia um cientista treinado como Lawrence, chefe do laboratório que abrigava o mais potente acelerador de partículas do mundo, deixar escapar o objeto de sua pesquisa? É importante lembrar que os dados referentes a uma observação, no entanto, não estão inertes esperando a intervenção dos cientistas para serem descobertos. Eles precisam ser recebidos pelo investigador; são uma construção, ou seja, estão imersos em uma subcultura (PICKERING, 1993). Neste caso em particular, o papel desempenhado pelos instrumentos na construção do conhecimento científico mais uma vez se faz presente, uma vez que muito frequentemente eles são referidos como aparatos que corporificam seu objeto de estudo (LENOIR, 2004). 
A produção de raios cósmicos em laboratório foi um feito singular. Além do mérito científico, há naqueles resultados um desdobramento sutil, mas de suma importância: o fato de o sincrocíclotron ter produzido píons assegurava que a tecnologia usada naquela máquina funcionava (MARQUES, 2005). Isso permitiria a construção de máquinas ainda mais potentes. Na mesma época, em 1950, já havia nos EUA dezenas de aceleradores de partículas, de tamanhos variados. Começava a chamada "Era das Máquinas", marcada por financiamento governamental volumoso, enormes laboratórios nacionais, estreitamento das relações com a indústria e o setor militar. A Europa, com o CERN; e a então União Soviética, com um laboratório em Dubna, seguiriam esses passos. Este movimento em direção a subsídios governamentais vultosos em criar nichos institucionais locais contribui prolificamente para a institucionalização de uma disciplina científica (BARACCA, 1976). A esse respeito, vemos que a intenção para a temática do financiamento da ciência nem sempre decorre de argumentos estritamente metafísicos. Interesses de diversas ordens se fazem presentes. No entanto, ainda que indiretamente, os interesses políticos que impulsionam a prática científica também confluem com a criação e manutenção de uma realidade difundida na disciplina a terceiros.

Até aqui, descreveu-se brevemente o processo de disciplinarização pelo qual passou a física de partículas elementares. Isso foi realizado com o propósito de mostrar a potencialidade deste episódio a professores tanto por sua relevância histórica, quanto por sua capacidade de incitar discussões que não são comumente abordadas nas salas de aula da universidade. A proeminência que os aceleradores e a instrumentação possuem nessa descrição sugerem que não é improvável que tal atribuição faça parte de uma estratégia elaborada pelos próprios cientistas em favor de uma certa concepção de prática científica (VIEIRA; VIDEIRA, 1998). A lembrança de que o méson $\pi$ fora observado antes na natureza, nos Pirineus franceses e nos Andes bolivianos, parece ser feita apenas para assegurar algum papel à natureza no processo de validação empírica de hipóteses científicas. Papel que com a fabricação e o uso das "grandes máquinas" seria cada vez mais relativizado, uma vez que estas últimas passaram a ser vistas como mais confiáveis. Seu uso proporcionaria maior segurança à crescente comunidade de físicos para que continuassem estudando a estrutura da matéria a partir do reducionismo uma das marcas características mais emblemáticas da ciência moderna. As máquinas não mais poderiam ser vistas como substitutas da natureza, uma vez que a relação do cientista com elas não se daria da mesma maneira que com a primeira. Ou seja, se, por um lado, a comunidade científica devesse sujeitar-se ao "ritmo" da natureza; por outro, a presença dos aceleradores passaria a ditar o rumo da prática científica. Desta maneira, tal como no caso com a natureza, os cientistas teriam que aprender a lidar com uma situação que, mesmo guardando alguma semelhança com o passado, não mais poderia ser vivenciada com as experiências então coletadas e organizadas. Uma nova prática ${ }^{5}$ começa a emergir, produzindo novos proce-

\footnotetext{
5 É importante ressaltar que não se está sugerindo neste trabalho que a instituição desta área como disciplina tenha surgido como efeito direto do uso desses instrumentos. No entanto, na rede dos inúmeros fatores causais, a presença dos aceleradores no processo de consolidação dessa disciplina pode ser caracterizada, pelo menos, como uma dentre muitas outras causas relevantes.
} 
dimentos pedagógicos. A formação do cientista passa a não ser mais individualizada: seria necessário contar (e rapidamente) com um grande número de pessoas, como cientistas e técnicos, capazes de trabalhar nos laboratórios. Uma formação pensada na coletividade passou a ser uma das prioridades do início da segunda metade do século XX (TAVARES, 2017), o que contribuiu e continua contribuindo para o surgimento de novos campos disciplinares como aquele que ora analisamos neste artigo.

\section{Considerações finais}

Não parece haver, na literatura de ensino de física, muitos trabalhos acerca da consolidação de uma nova área como disciplina científica. Embora elas sejam o primeiro contato que os alunos têm com a explicação de fenômenos físicos por meio do uso de leis, teorias e modelos; nos livros ou nos cursos de física, não vemos nenhuma menção ao modo pelo qual as disciplinas são constituídas. No entanto, é importante para a prática docente conhecer um pouco acerca deste processo de formação, uma vez que elas deixam de ser tratadas como estruturas que organizam a ciência para passarem a ser vistas como estruturas dinâmicas que se modificam e impulsionam a ciência. Não seria exagero afirmar que o estudo da consolidação de uma disciplina não só mune os educadores de argumentos sobre como o conhecimento da sua área é criado, mas também desempenha papel no desenvolvimento da análise crítica e da compreensão de uma certa imagem de ciência. Como exemplo concreto, tentamos investigar os percursos que culminaram no aparecimento da Física de Partículas Elementares como disciplina autônoma. Para isto, enfatizamos o caráter de circulação e estabilização dos produtos científicos. Além disso, esperamos ter mostrado, embora com algumas limitações, que esta disciplina não surgiu por ocasião da descoberta do méson $\pi$ na natureza - ao contrário do que afirma a historiografia atual. Sua consolidação se verificou, entre outros motivos, pela criação desta partícula em uma situação artificial, em um instrumento concebido pela atividade humana. De maneira sintética, esperamos ter oferecido argumentos convincentes de que o episódio de constituição de uma nova área tem em si muitas potencialidades didáticas que podem ser exploradas em sala de aula. Com este efeito, espera-se que os professores se interessem em conhecer as técnicas, práticas e culturas de uma disciplina ao invés de aterem-se somente aos seus resultados finais. Essa abordagem abre caminho ao pensamento crítico e propicia uma oportunidade para professores e alunos raciocinarem analiticamente sobre a matéria em apreço.

\section{Referências Bibliográficas}

BARACCA, A.Qu'est-ce qui fait courir les hautes energies? Fondements des Sciences, n. 58, 1976. Université Louis Pasteur de Estrasbourg. 
BROWn, L. M.; HODdeSON, L. (Org.). The Birth of Particle Physics. Cambridge: Cambridge University Press, 1983.

CARTWRIGHT, N. How the laws of physics lie. Oxford: Clarendon Press, 1988.

CARUSO, F.; OGURI, V. A eterna busca do indivisível: do átomo filosófico aos Quarks e Léptons. Química Nova, v. 20, n. 3, 1997.

ENNIS, R. Research in Philosophy of Science Bearing on Science Education" In: ASQUITH, P. D.; KYBURG, H. E. (Org.). Current Research in Philosophy of Science, 1979.

FOSteR, B.; FOWleR, P. H. (Org.) 40 Years of Particle Physics. Bristol: Adam Hilger, 1988.

GALISON, P. Image and Logic: A Material Culture of Microphysics. Chicago: University of Chicago Press, 1997.

GUNTAU, M; LAITKO, H. On the origin and nature of scientific disciplines In: World Views and Scientific Formation, p. 17-28, 1991.

HACKING, I. Representing and Intervening, Cambridge: Cambridge University Press, 1983.

KRAGH, H. Quantum Generations: A History of Physics in the Twentieth Century. Princeton: Princeton University Press, 2002.

KUHN, T. S. A estrutura das revoluções científicas. Tradução: Paulo Aukar. 1. ed. Santa Maria, RS, 2016.

LENOIR, T. Instituindo a ciência: a produção cultural das disciplinas científicas. Tradução: Alessandro Zir. São Leopoldo: Unisinos, 2004.

LEPRINCE-RINGUET, L. Discours de Clôture. In: CONGRES INTERNATION SUR LES RAYONS COSMIQUES, 1953, Bagnères de Bigorre, Université de Toulouse. p. 287-290.

LOPES, J. L. Uma história da Física no Brasil. São Paulo: Livraria da Física, 2004.

MARQUES, A. Em memória de César Lattes. Série Ciência e Sociedade CBPF- CS-004/05, Rio de Janeiro, 2005. Disponível em:

$<$ http://cbpfindex.cbpf.br/publication_pdfs/cs00405.2010_08_11_13_04_39.pdf>. Acesso em: 25 ago. 2017.

MATTHEWS, M. Science Teaching: The role of History and Philosophy of Science. Routledge, 1994.

MENDONÇA, A. L. O. O legado de Thomas Kuhn após cinquenta anos. Scientiae Studia, São Paulo, v. 10, n. 3, 2012. 
OCCHIALINI, G. P. S.; POWELL, C. F. Nuclear disintegrations produced by slow charged particles of small mass. Nature, v. 159 (4032), p. 186-90, 1947.

OLIVEIRA, A. B. Sistema Nacional de Inovação e o valor epistêmico originalidade nas ciências. Em construção, v. 1, p. 81-105, 2017.

PICKERING, A. From science as knowledge to science as practice, In: Pickering, A. (Org.). Science as practice and culture. Chicago: University of Chicago Press, 1992. p. 1-28.

PIETROCOLA, M.; SIQUEIRA, M. Como a Física de Partículas Elementares pode contribuir no Ensino Básico? In: CARUSO, F.; OGURI, V.; SANTORO, A. (Orgs.) O que são Quarks, Glúons, Higgs, Buracos Negros e outras coisas estranhas? São Paulo: Editora Livraria da Física, 2011.

SCHENBERG, M. Formação da mentalidade científica. Estudos Avançados, v. 5, n. 12, São Paulo, 1991.

SCHWAB, J. J. Structure of the Disciplines: Meaning \& Significances. In: FORD, G. W.; PUGNO, L. (Org.). The Structure of Knowledge \& the Curriculum. Chicago: Rand McNa11y \& Co., 1964.

SILVA, V. C. Qual é o valor da ciência? Metafísica e axiologia na Big Science e na tecnologia. 2017. 247 f. Tese (Doutorado em Filosofia) - IFCH, UERJ, Rio de Janeiro.

STANLEY, M. Why study history? Physics Today, v. 69, n. 7, p. 38-44, 2016.

STICHWEH, R. The Sociology of Scientific Disciplines. Science in Context, v. 5, Issue 1; p. 3-15, 1992.

TAVARES, H. D. Estilo de pensamento em física nuclear e de partículas no Brasil (19341975): César Lattes entre raios cósmicos e aceleradores. 2017. 255 f. Tese (Doutorado em História das Ciências e das Técnicas e Epistemologia) - HCTE, UFRJ, Rio de Janeiro.

VIDEIRA, A. A. P. A Inevitabilidade da Filosofia Natural do Século 19: O Caso da Física Teórica. Ijuí: Editora Unijuí, 2013.

VIDEIRA, A. A. P. A Filosofia da Ciência sob o Signo dos Science Studies. Abstracta, v. 2, n. 1, p. 70-83, 2005. Disponível em:

$<$ http://www.abstracta.pro.br/revista/volume2number1/4_videira.pdf>. Acesso em: 25 ago. 2017.

VIEIRA, C. L.; VIDEIRA, A. A. P. Carried by history: Cesar Lattes, Nuclear Emulsions, and the Discovery of the Pi-meson. Physics in Perspective, v. 16, n. 1, p. 3-36, 2014.

VIEIRA, C. L. Um mundo inteiramente novo se revelou: uma história da técnica das emulsões nucleares. São Paulo: Editora Livraria da Física, 2012. 
ZIMAN, J. A força do conhecimento. São Paulo: Edusp, 1981.

WEINBERG, S. The Discovery of Subatomic Particles. Cambridge: Cambridge University Press, 2013. 